Supporting Information

\title{
Heterostructured Lepidocrocite Titanate-Carbon Nanosheets for Electrochemical Applications
}

Gözde Barim ${ }^{1}$, Rohan Dhall ${ }^{2}$, Elisabetta Arca ${ }^{1}$, Tevye R. Kuykendall, ${ }^{3}$ Wei Yin, ${ }^{1}$ Kenneth J. Takeuchi, ${ }^{4,5,6}$ Esther S. Takeuchi, ${ }^{4,5,6}$ Amy C. Marschilok, ${ }^{4,5,6}$ and Marca M. Doeff ${ }^{1, *}$

1. Energy Storage \& Distributed Resources Division, Lawrence Berkeley National Laboratory, Berkeley, CA 94720, United States.

2. National Center for Electron Microscopy, Molecular Foundry, Lawrence Berkeley National Laboratory, Berkeley, CA 94720, United Statews.

3. Molecular Foundry, Lawrence Berkeley National Laboratory, Berkeley, CA 94720, United States.

4. Department of Chemistry, Stony Brook University, Stony Brook, NY 11794, United States.

5. Department of Materials Science and Chemical Engineering, Stony Brook University, Stony Brook, NY 11794, United States.

6. Interdisciplinary Science Department, Brookhaven National Laboratory, Upton, NY 11973 United States.

${ }^{*}$ E-mail: mmdoeff@lbl.gov

a)

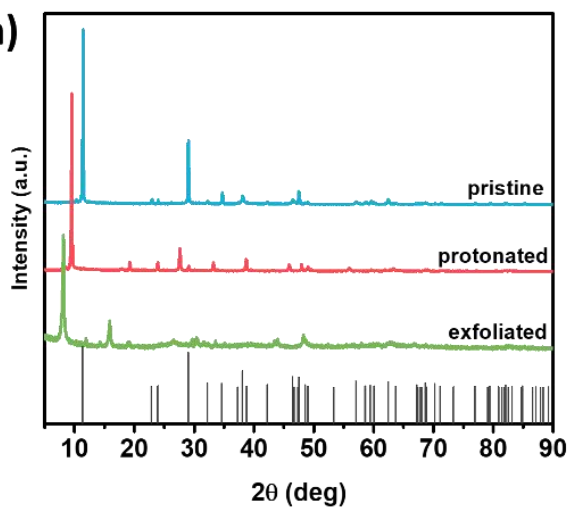

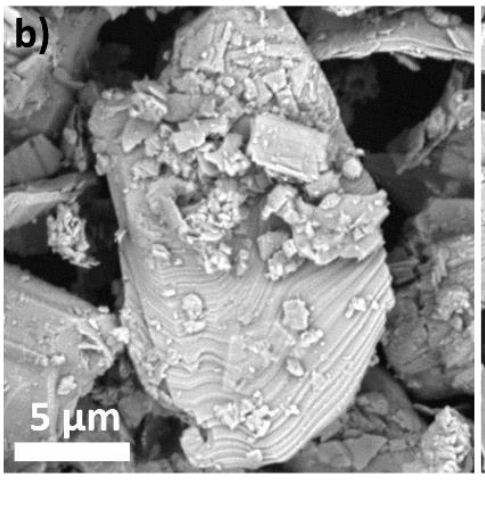

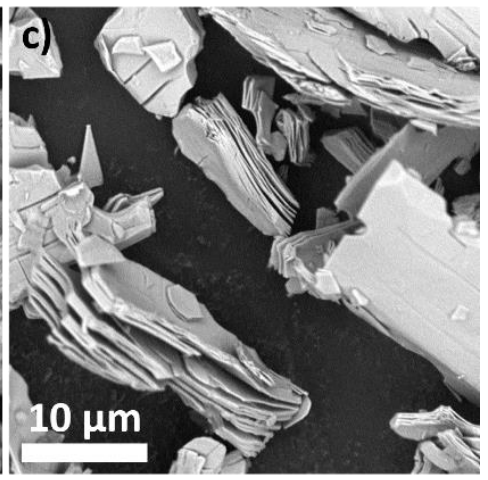

Figure S1: (a) XRD patterns of pristine lepidocrocite titanate $\left(\mathrm{K}_{0.8} \mathrm{Ti}_{1.73} \mathrm{Li}_{0.27} \mathrm{O}_{4}\right)$ and its protonated form as well as titania nanosheets after exfoliation, and SEM micrographs of (b) as-synthesized and (c) protonated forms of lepidocrocite titanate. A stick pattern from the PDF card of the pristine material (KTL) is marked in black. 


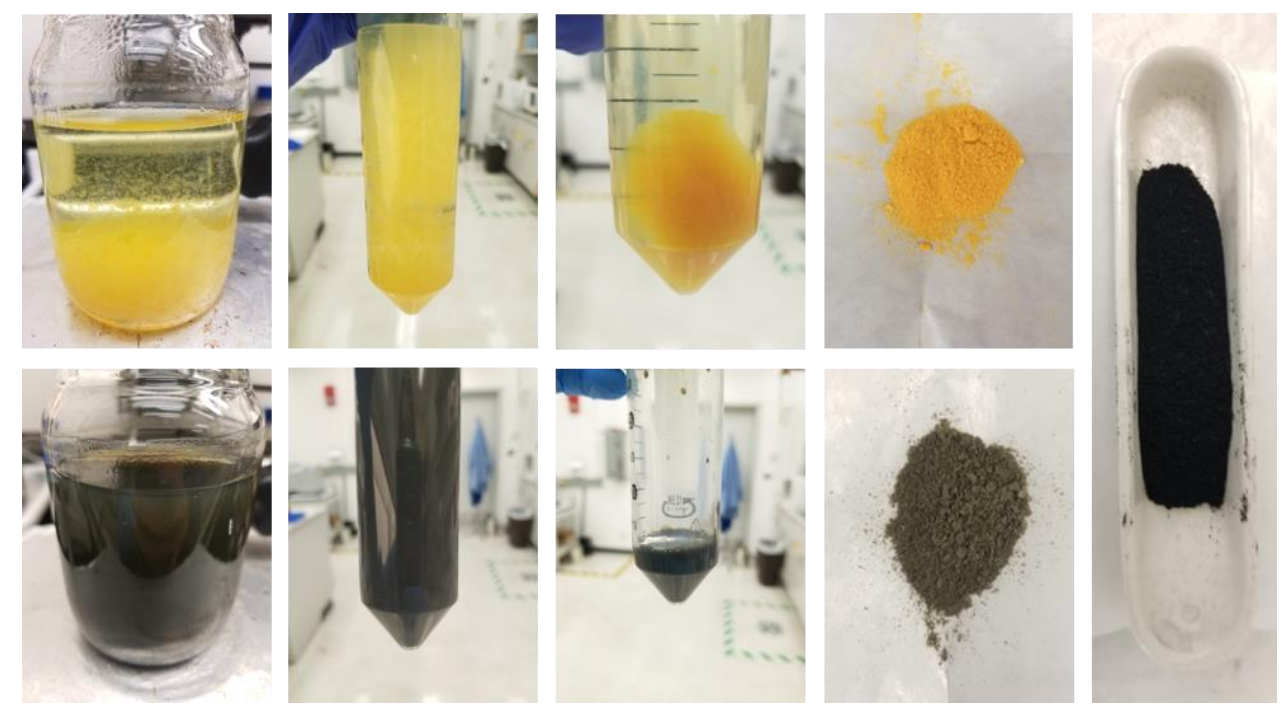

Figure S2: Flocculated LTO-Dopa suspensions obtained by self-assembly at pH 7 (top) and pH 11.5 (bottom) and a black carbonized powder on the right.

Table S1. Conditions used to make various samples, their carbon and water contents, and dspacings.

\begin{tabular}{lllllll}
\hline $\begin{array}{l}\text { Type of } \\
\text { Material }\end{array}$ & $\mathbf{p H}$ & $\begin{array}{l}\text { Dopa/LTO } \\
\text { molar } \\
\text { ratio }\end{array}$ & $\begin{array}{l}\text { Stirring } \\
\text { time, } \mathbf{m i n}\end{array}$ & $\begin{array}{l}\mathbf{C} \text { content, } \\
\mathbf{\%} \mathbf{w} / \mathbf{w}\end{array}$ & $\begin{array}{l}\text { Water content, } \\
\mathbf{\%} \mathbf{w} / \mathbf{w}\end{array}$ & $\begin{array}{l}\text { d-spacing, } \\
\mathbf{n m}^{\mathbf{a}}\end{array}$ \\
\hline LTO-DOPA & 7 & 5.0 & 60 & 14.8 & 22.2 & 1.33 \\
LTO-DOPA & 11.5 & 5.0 & 60 & 15.1 & 27.3 & 1.52 \\
LTO-C & 7 & 5.0 & 60 & 20.5 & 9.5 & 1.00 \\
LTO-C & 11.5 & 5.0 & 60 & 25.5 & 10 & 1.06 \\
LTO-C & 7 & 5.0 & 5 & 20 & 7.3 & 1.02 \\
LTO-C & 11.5 & 5.0 & 5 & 23.4 & 10 & 1.02 \\
LTO-C & 11.5 & 0.66 & 5 & 21.4 & 6.2 & 1.04 \\
LTO-C & 11.5 & 1.0 & 5 & 21.5 & 9.4 & 1.05 \\
LTO-C & 11.5 & 3.0 & 5 & 23.3 & 10 & 0.98 \\
LTO-C & 7 & 1.0 & 5 & 17.5 & 5.1 & 1.16 \\
LTO-C & 11.5 & 10 & 60 & 30 & 8 & 0.775 \\
KTL* & N/A & N/A & N/A & N/A & N/A \\
\hline
\end{tabular}

a) (020) reflection for KTL, and, by analogy, for heterostructures.

* Taken from reference $17 . \mathrm{KTL}=\mathrm{K}_{0.8} \mathrm{Ti}_{1.73} \mathrm{Li}_{0.27} \mathrm{O}_{4}$. 

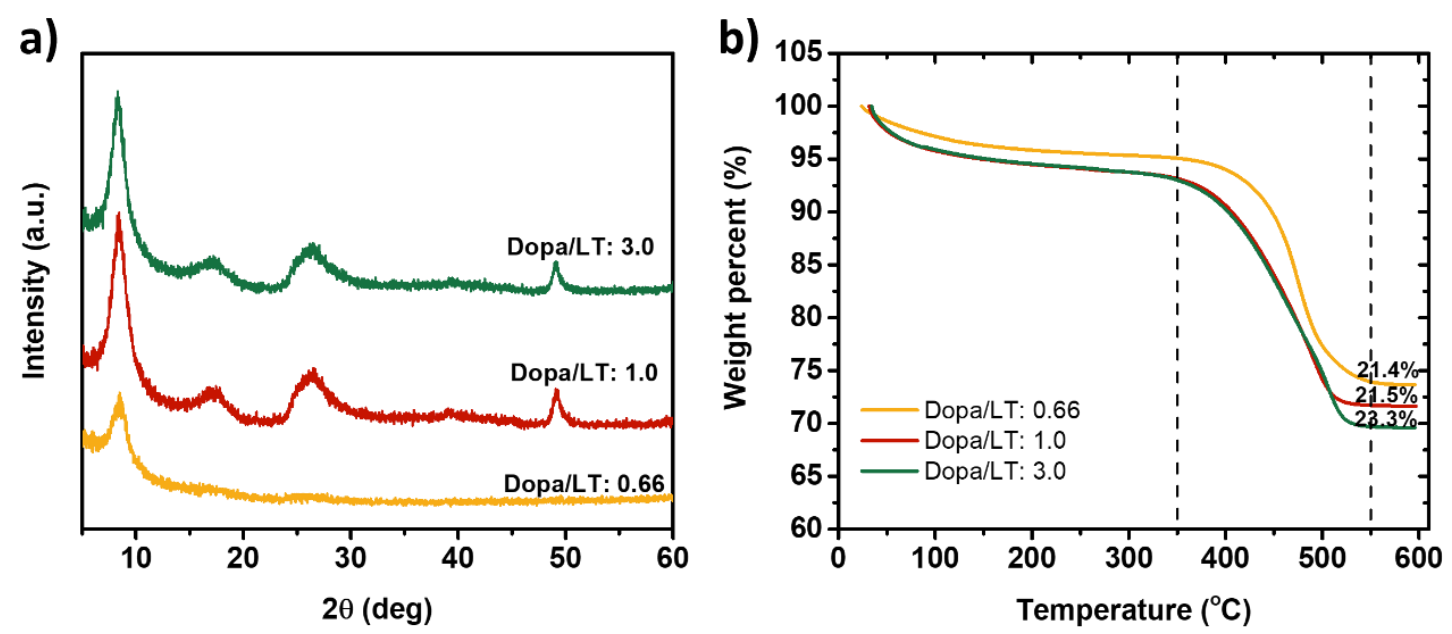

Figure S3: (a) XRD patterns of lepidocrocite titanate - dopamine heterostructures stirred $5 \mathrm{~min}$ at $\mathrm{pH}$ 11.5, after carbonization, using different Dopa/LTO ratios and (b) TGA weight loss curves for the same materials.
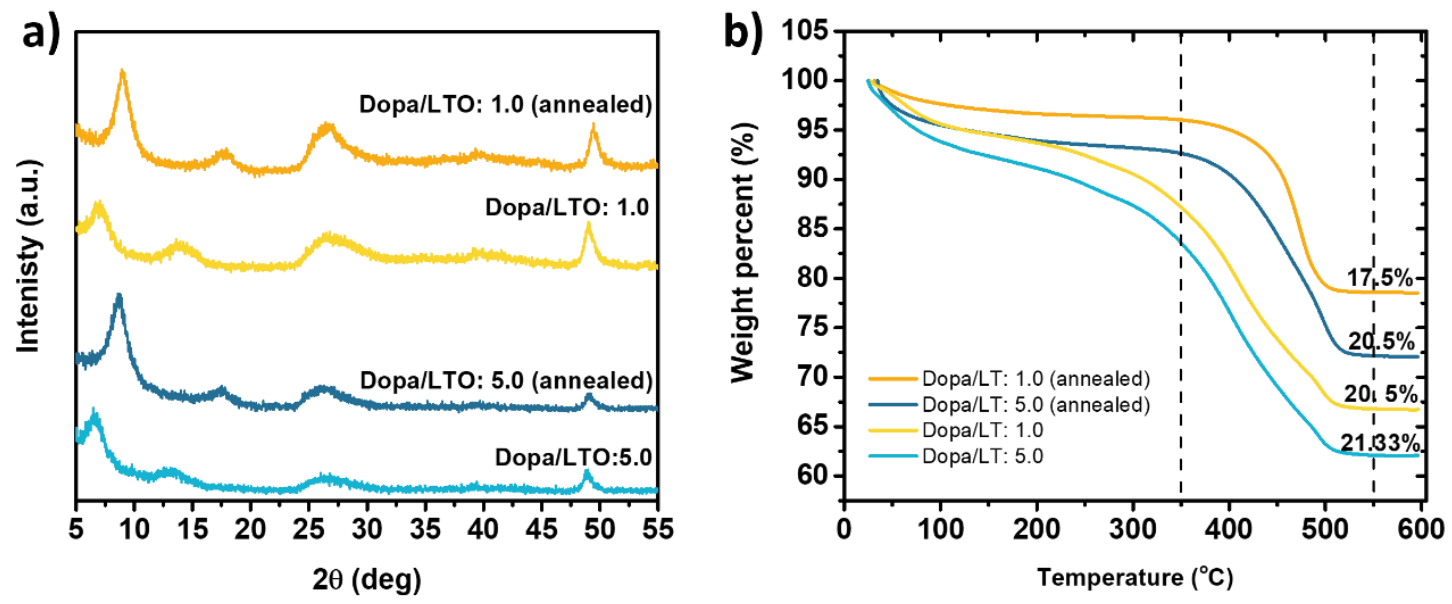

Figure S4: (a) XRD patterns of lepidocrocite titanate - dopamine heterostructures stirred 5 minutes at $\mathrm{pH} 7$ before and after carbonization at $600{ }^{\circ} \mathrm{C}$ for $2 \mathrm{~h}$ under Argon, and (b) TGA weight loss curves. 

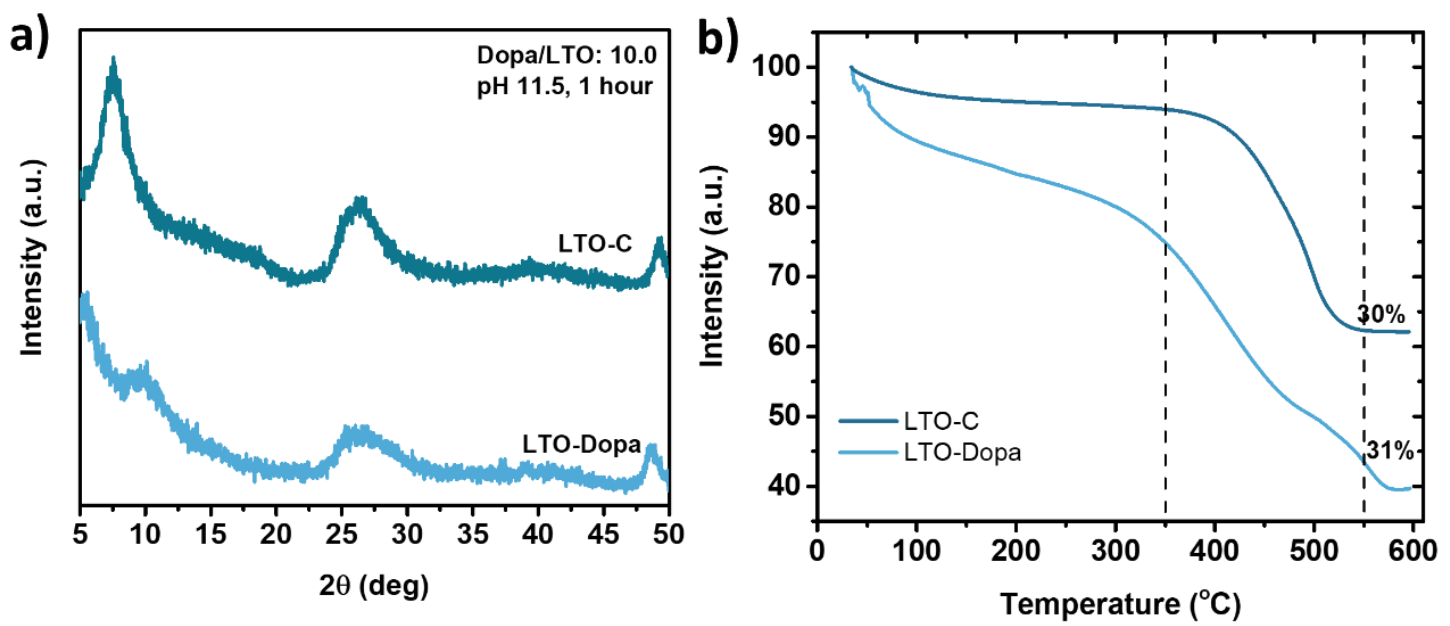

Figure S5: (a) XRD patterns and (b) TGA weight loss curves of lepidocrocite titanate - dopamine heterostructures prepared with a DOPA:LTO ratio of 10.0 stirred for one hour at $\mathrm{pH} 11.5$ before and after carbonization at $600{ }^{\circ} \mathrm{C}$ for $2 \mathrm{~h}$ under Argon.
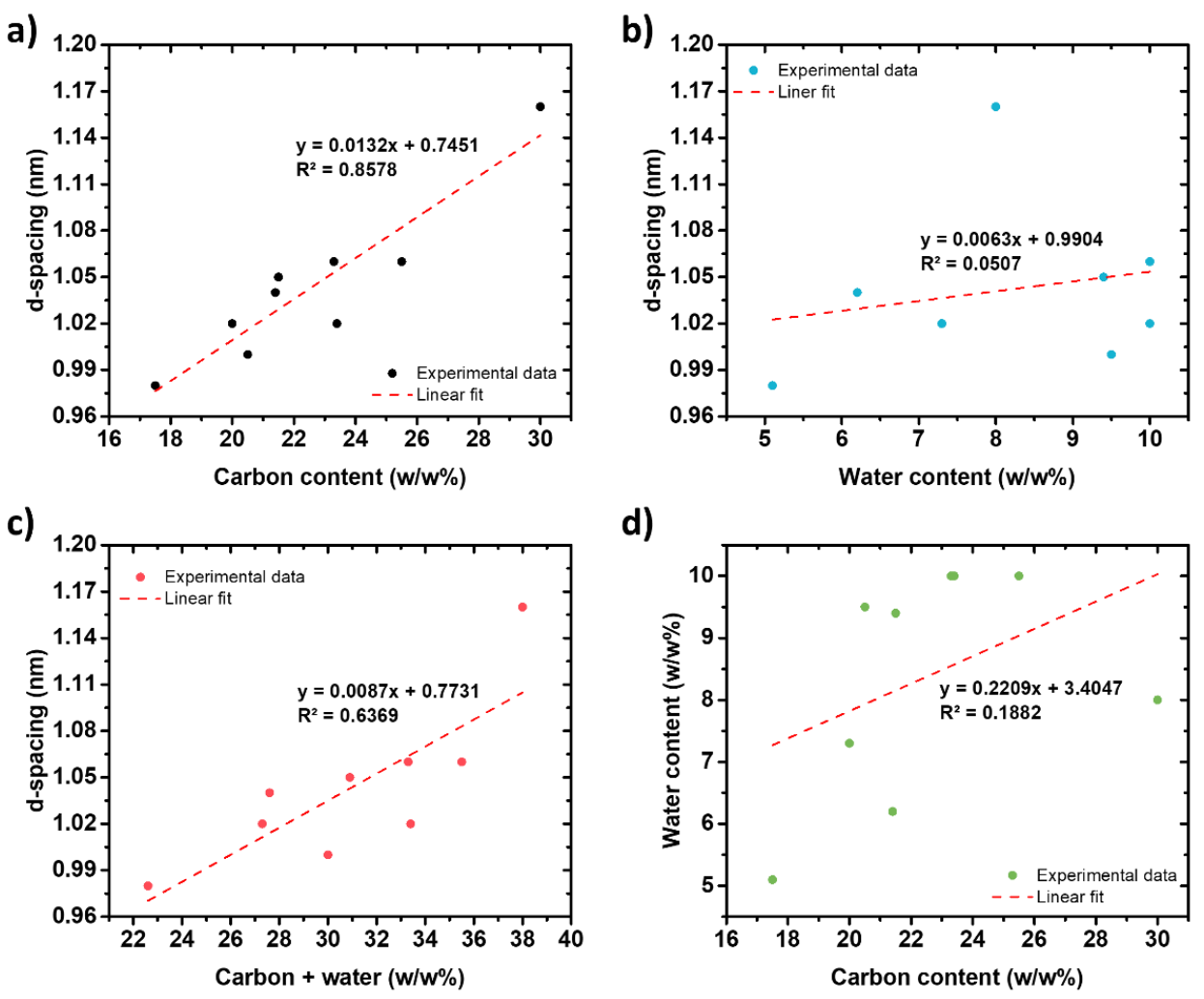

Figure S6: Correlation between (a) carbon content and d-spacing (b) water content and d-spacing (c) sum of carbon and water content and d-spacing and (d) carbon content and water content of lepidocrocite titanate - carbon heterostructures after carbonization at $600{ }^{\circ} \mathrm{C}$. 
a)

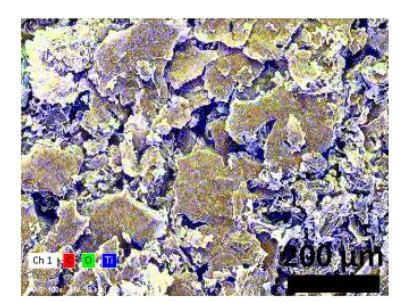

b)

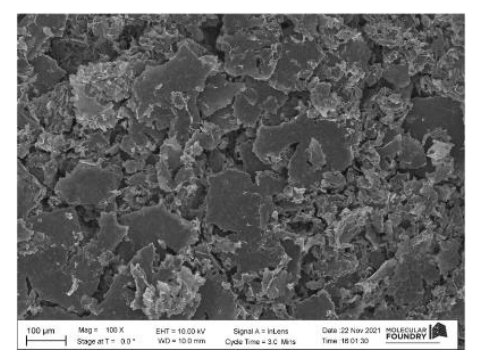

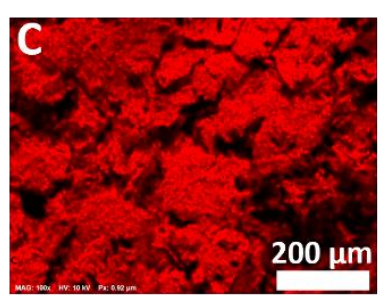

c)
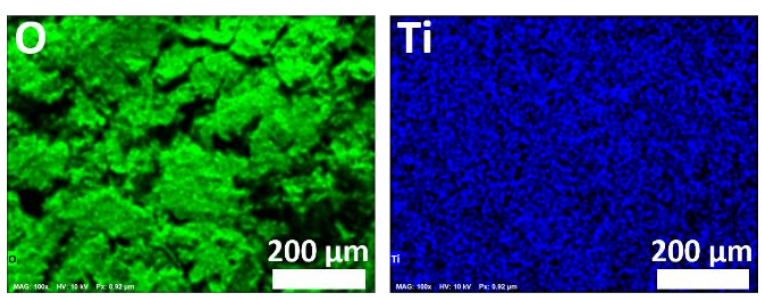

\begin{tabular}{|c|c|c|c|c|c|c|c|}
\hline Element & At. No. & Netto & $\begin{array}{c}\text { Mass } \\
{[\%]}\end{array}$ & $\begin{array}{c}\text { Mass Norm. } \\
{[\%]}\end{array}$ & $\begin{array}{c}\text { Atom } \\
{[\%]}\end{array}$ & $\begin{array}{c}\text { abs. error [\%] } \\
\text { (1 sigma) }\end{array}$ & $\begin{array}{c}\text { rel. error [\%] } \\
\text { (1 sigma) }\end{array}$ \\
\hline Carbon & 6 & 211610 & 26.96 & 28.56 & 48.56 & 2.95 & 10.96 \\
\hline Oxygen & 8 & 84399 & 23.29 & 24.68 & 31.50 & 2.67 & 11.48 \\
\hline \multirow[t]{2}{*}{ Titanium } & 22 & 177636 & 44.13 & 46.76 & 19.94 & 1.54 & 3.49 \\
\hline & & Sum & 94.38 & 100.00 & 100.00 & & \\
\hline
\end{tabular}

Figure S7: (a) Elemental mapping by SEM EDS, (b) low magnification SEM micrograph and (c) elemental analysis of LTO-30\%C heterostructure.

a)

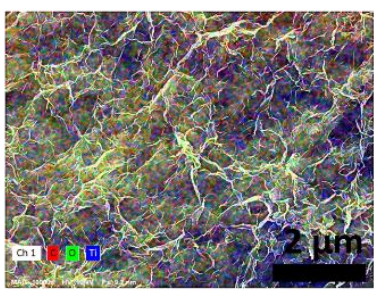

b)

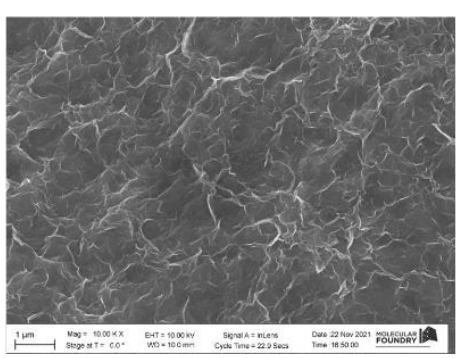

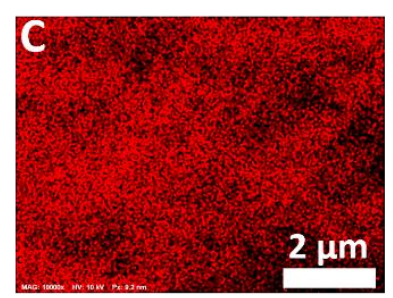

c)

\begin{tabular}{|c|c|c|c|c|c|c|c|}
\hline Element & At. No. & Netto & $\begin{array}{c}\text { Mass } \\
{[\%]}\end{array}$ & $\begin{array}{c}\text { Mass Norm. } \\
{[\%]}\end{array}$ & $\begin{array}{c}\text { Atom } \\
{[\%]}\end{array}$ & $\begin{array}{c}\text { abs. error [\%] } \\
\text { (1 sigma) }\end{array}$ & $\begin{array}{l}\text { rel. error [\%] } \\
\text { (1 sigma) }\end{array}$ \\
\hline Carbon & 6 & 379404 & 40.63 & 36.25 & 54.43 & 4.35 & 10.71 \\
\hline Oxygen & 8 & 146903 & 32.19 & 28.72 & 32.38 & 3.58 & 11.12 \\
\hline \multirow[t]{2}{*}{ Titanium } & 22 & 178387 & 39.27 & 35.03 & 13.20 & 1.37 & 3.50 \\
\hline & & Sum & 112.09 & 100.00 & 100.00 & & \\
\hline
\end{tabular}

Figure S8: (a) Elemental mapping by SEM EDS, (b) high magnification SEM micrograph and (c) elemental analysis of LTO-30\%C heterostructure. 
a)

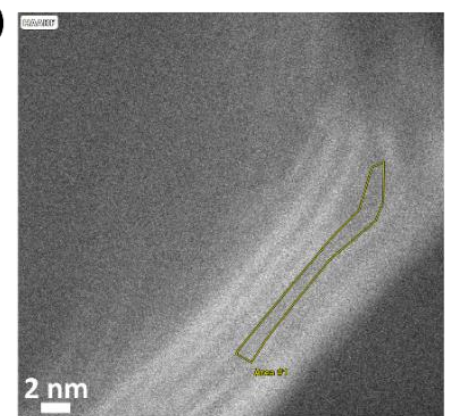

b)

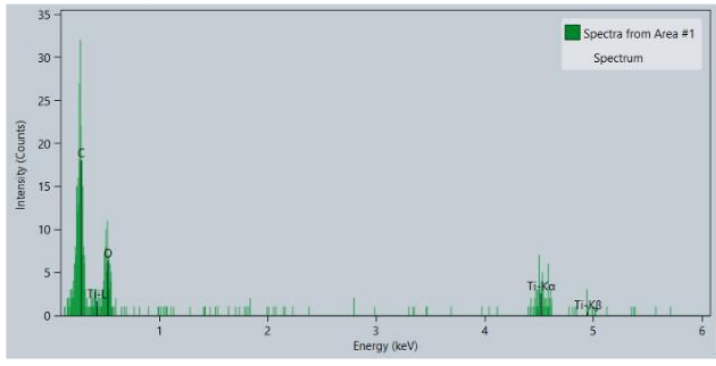

c) Z Element Family Atomic Fraction (\%) Atomic Error (\%) Mass Fraction (\%) Mass Error (\%) Fit error (\%)

$\begin{array}{cccccccc}6 & \mathrm{C} & \mathrm{K} & 80.70 & 6.84 & 69.38 & 3.94 & 3.14 \\ 8 & \mathrm{O} & \mathrm{K} & 15.57 & 3.48 & 17.83 & 3.82 & 6.09 \\ 22 & \mathrm{Ti} & \mathrm{K} & 3.73 & 0.63 & 12.79 & 2.01 & 7.01\end{array}$

Figure S9: (a) HAADF micrograph of LTO-30\%C heterostructure, (b) and (c) EDS analysis of marked dark area in HAADF image.

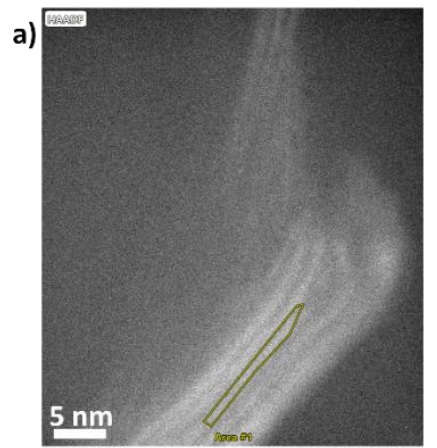

b)

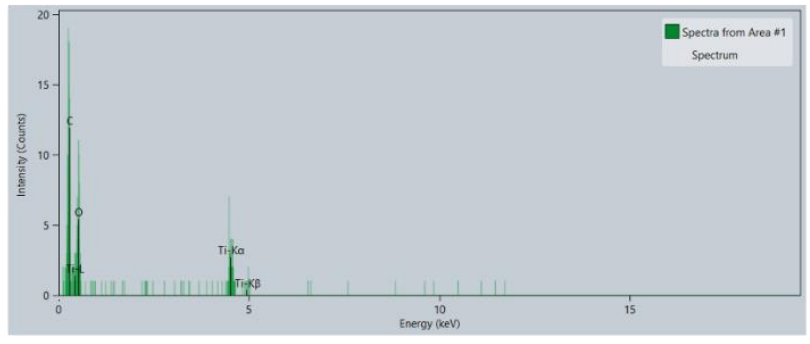

c) Z Element Family Atomic Fraction (\%) Atomic Error (\%) Mass Fraction (\%) Mass Error (\%) Fit error (\%)

$\begin{array}{cccccccc}6 & \mathrm{C} & \mathrm{K} & 75.63 & 8.82 & 61.63 & 4.99 & 5.34 \\ 8 & \mathrm{O} & \mathrm{K} & 18.85 & 4.50 & 20.46 & 4.57 & 7.81 \\ 22 & \mathrm{Ti} & \mathrm{K} & 5.51 & 0.99 & 17.90 & 2.85 & 6.39\end{array}$

Figure S10: (a) HAADF micrograph of LTO-30\%C heterostructure, (b) and (c) EDS analysis of marked bright area in HAADF image. 

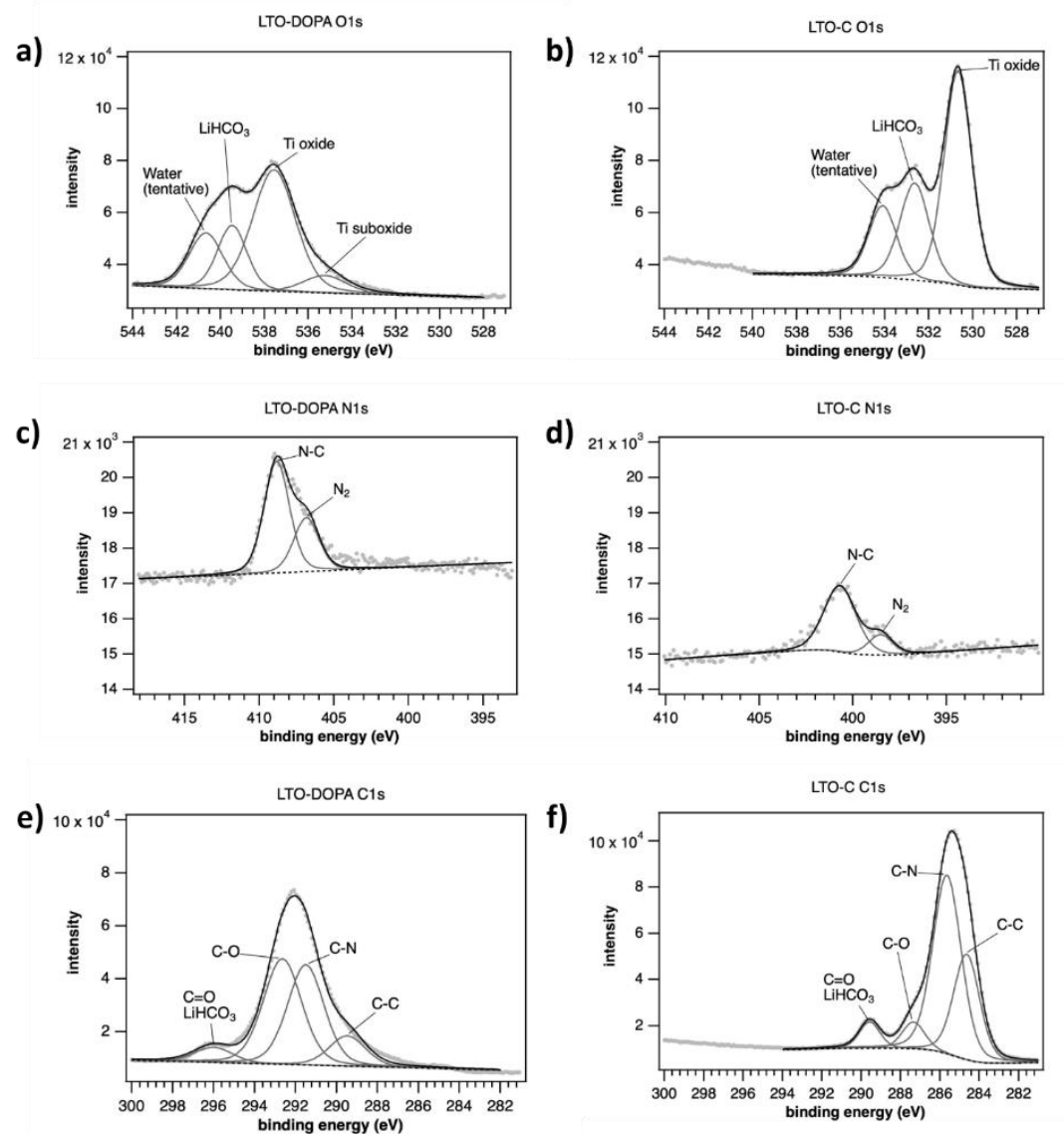

Figure S11: Comparison between the (a,b) O 1s (c,d) N 1s and (e,f) C 1s core-levels recorded for LTO-DOPA and LTO-23.4\%C samples. Peak fitting was conducted using a Gaussian-Lorentzian function (Gauss-Lorentz Ratio $=0.3$ ).

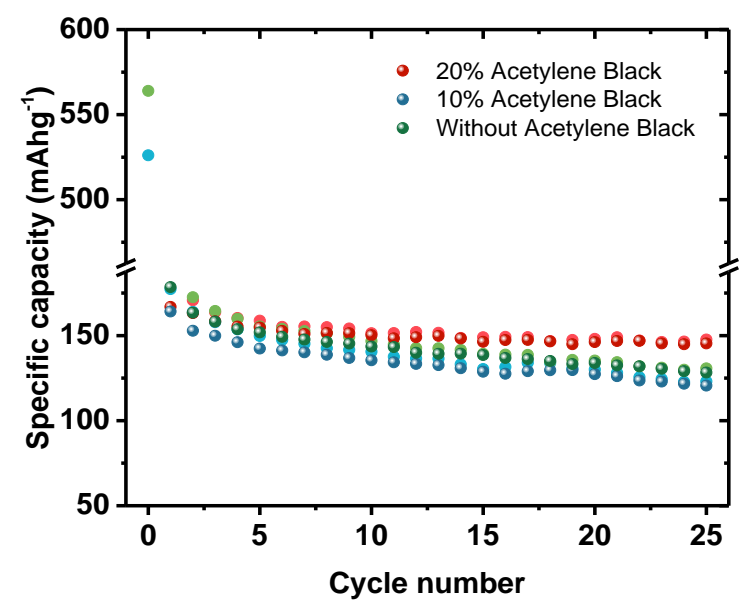

Figure S12: Cycling performance of sodium cells containing LTO-30\%C heterostructures with various amounts of acetylene black additive in the electrode at $0.15 \mathrm{~mA} \mathrm{~cm}^{-2}$ for 25 cycles. 
Initial, $\mathrm{Na}: \mathrm{Ti}=\mathbf{0}$

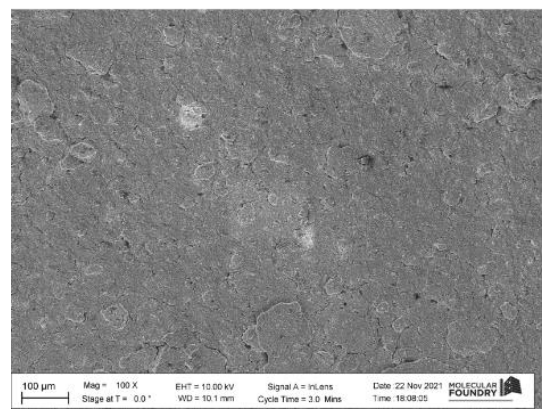

$2^{\text {nd }}$ cycle , Na:Ti=0.41

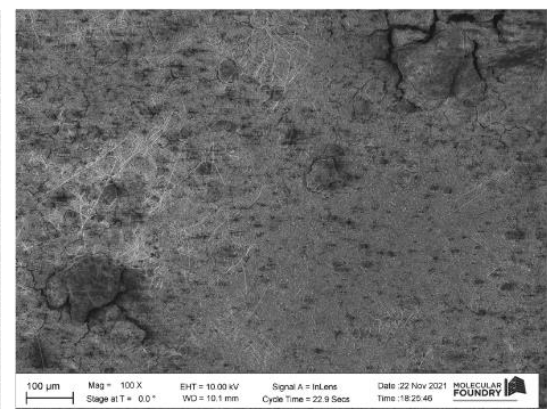

$31^{\text {st }}$ cycle , Na:Ti=0.72

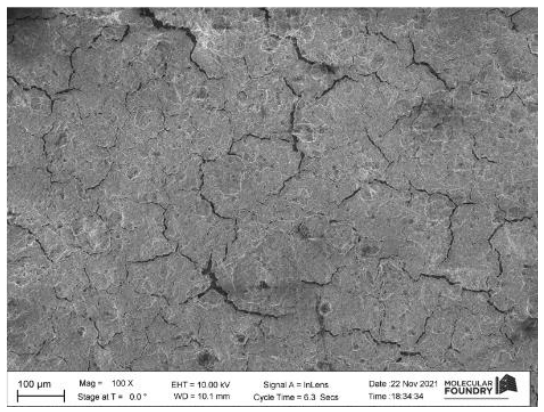

Figure S13: SEM micrographs of electrodes prepared with LTO-23.4\%C heterostructure and PVDF binder (without carbon additives) in sodium half-cells with $0.5 \mathrm{M} \mathrm{NaBPh}_{4}$ in DEGDME electrolyte before cell assembly and after $2^{\text {nd }}$ and $31^{\text {st }}$ cycles.
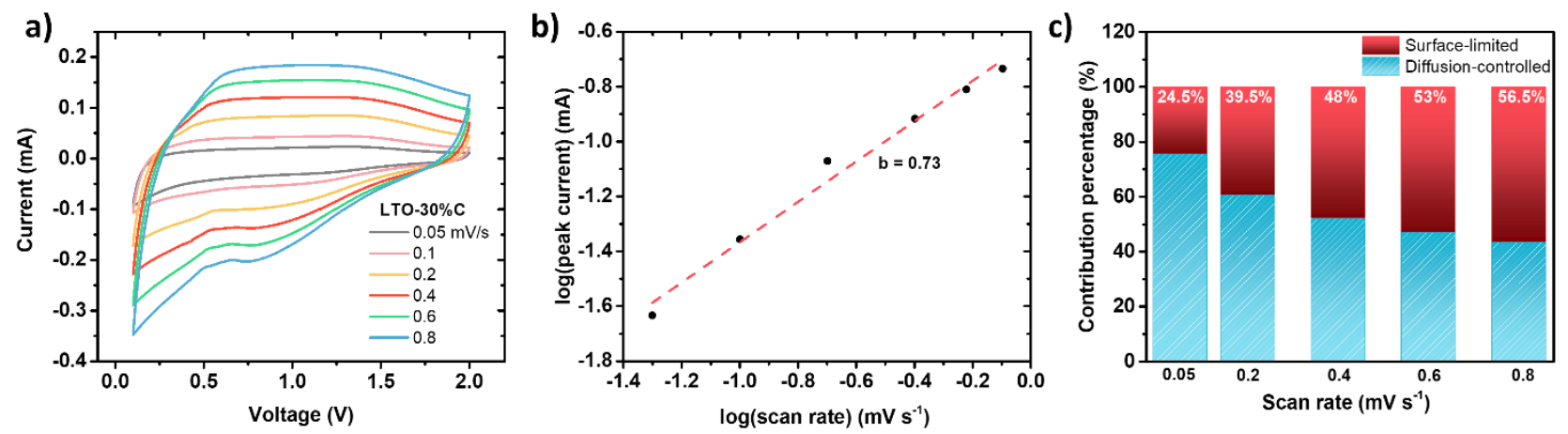

Figure S14: (a) Cyclic voltammograms of LTO-C heterostructures with $30 \%$ carbon at various scan rates from 0.05 to $0.8 \mathrm{mV} \mathrm{s}^{-1}$, (b) logarithmic plots of peak currents as a function of scan rates, (c) normalized contributions of diffusion-controlled and surface-limited reactions at different scan rates. 

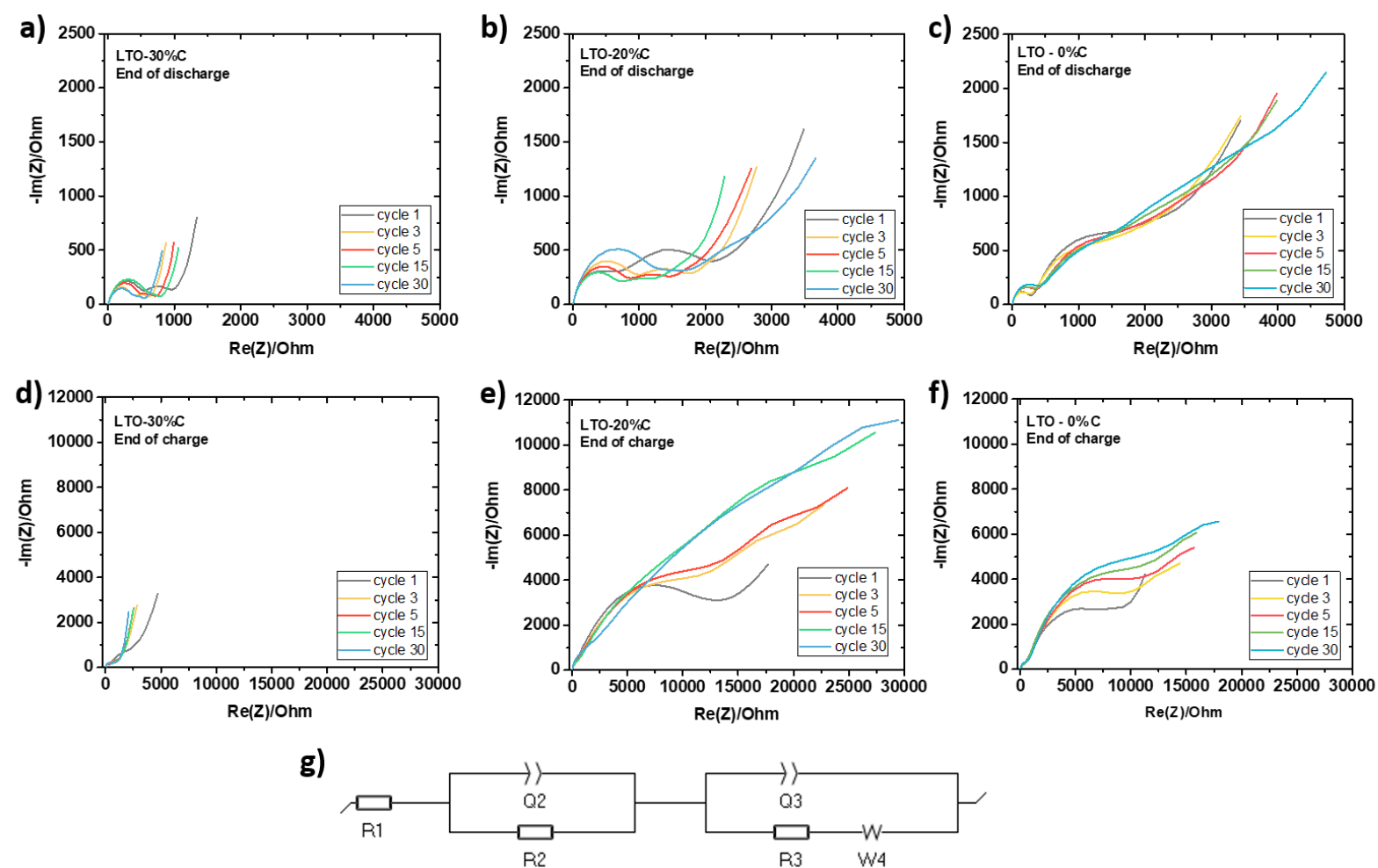

Figure S15: Nyquist plots of end of discharge and charge (a) and (d) Na/LTO-30\%C cell, (b) and (e) $\mathrm{Na} / \mathrm{LTO}-20 \% \mathrm{C}$ cell (c) and (f) $\mathrm{Na} / \mathrm{LTO}-0 \% \mathrm{C}$ cell showing impedance data at the end of selected cycles. Cells were rested for half an hour before impedance data was collected. (g) Equivalent circuit used for impedance analysis.

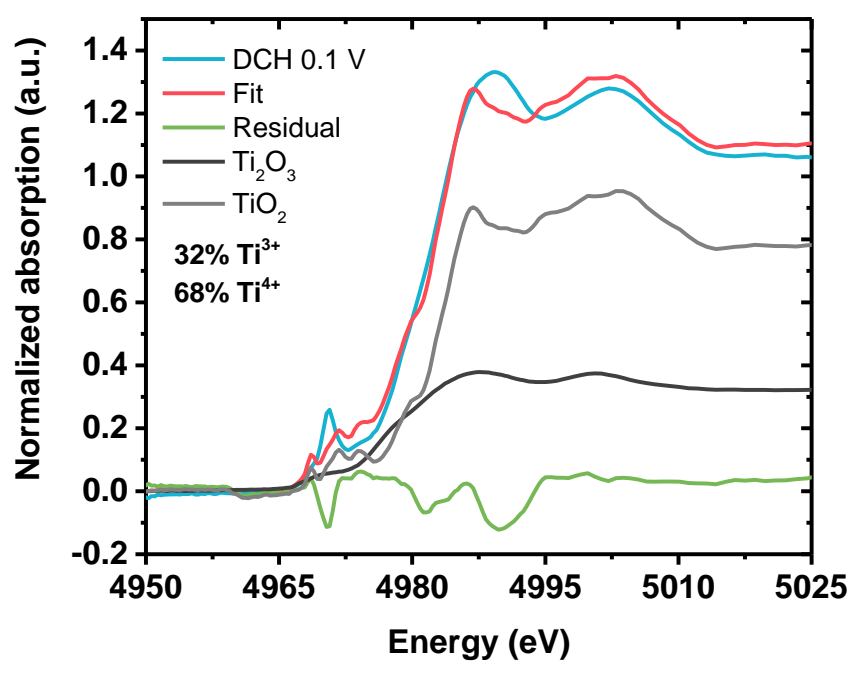

Figure S16: Linear combination fitting of discharged electrode at $0.1 \mathrm{~V}$ with $\mathrm{TiO}_{2}$ and $\mathrm{Ti}_{2} \mathrm{O}_{3}$ standards used in the XAS experiments. 


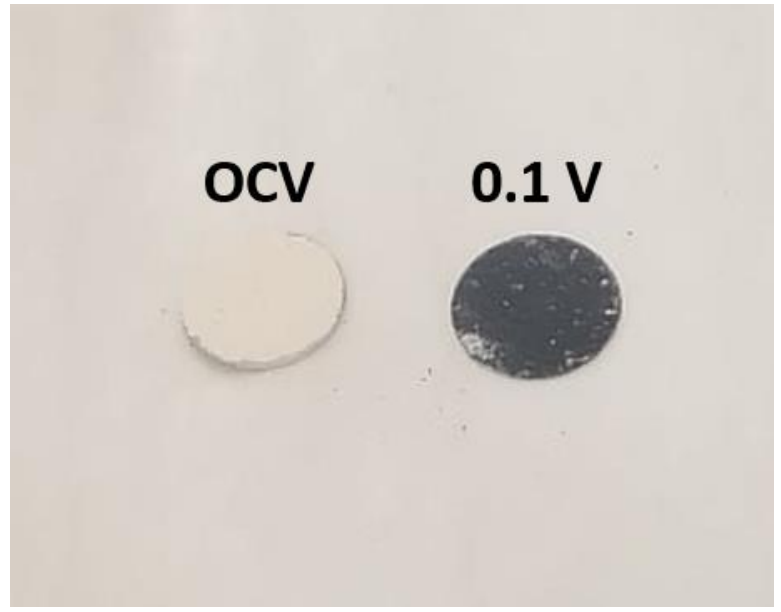

Figure S17: Optical images of carbon-free LTO electrodes at open circuit voltage before cycling and after discharging to $0.1 \mathrm{~V}$. 